\title{
TIME-VARYING UNCERTAINTY AND THE CREDIT CHANNEL
}

\author{
Victor Dorofeenko, * Gabriel S. Lee† and Kevin D. Salyer $\ddagger$
}

*Department of Economics and Finance, Institute for Advanced Studies, Austria, †Department of Real Estate, University of Regensburg, Germany, and Institute for Advanced Studies, Austria, and $\ddagger$ Department of Economics, University of California at Davis, California, USA

\section{ABSTRACT}

We extend the Carlstrom and Fuerst (American Economic Review, 1997, 87, pp. 893-910) agency cost model of business cycles by including time-varying uncertainty in the technology shocks that affect capital production. We first demonstrate that standard linearization methods can be used to solve the model yet second moments enter the economy's equilibrium policy functions. We then demonstrate that an increase in uncertainty causes, ceteris paribus, a fall in investment supply. We also show that persistence of uncertainty affects both quantitatively and qualitatively the behaviour of the economy.

Keywords: agency costs, credit channel, time-varying uncertainty JEL classification numbers: E4, E5, E2

\section{INTRODUCTION}

The impact of risk on aggregate investment and lending activity, while extensively studied in theoretical models, has received little attention in quantitative macroeconomic settings. In large part, this has been due

Correspondence: Kevin D. Salyer, Department of Economics University of California, USA, Tel: (530) 7528359, Email: kdsalyer@ucdavis.edu. We wish to thank Timothy Cogley, John Fernald, Timothy Fuerst, Robert Rich, Kevin Stiroh and two anonymous referees for useful comments and suggestions. We also benefitted from comments received during presentations at the Society for Computational Economics, Summer 2003 meetings, Winter Econometric Soceity meeting 2003, S.E.D. 2003 meeting, UC Riverside, Simon Fraser University, Humboldt University and CERGE-EI. We are especially indebted to participants in the UC Davis and IHS Macroeconomics Seminar for insightful suggestions that improved the exposition of the paper.We also gratefully acknowledge financial support from Jubiläumsfonds der Oesterreichischen Nationalbank (Jubiläumsfondsprojekt No. 9220). 
to computational methods, i.e., linearization methods, which impose certainty equivalence so that second moments play no role. We address this omission in this paper by using the credit channel model of Carlstrom and Fuerst (1997). In particular, we model time-varying uncertainty as a mean preserving spread in the distribution of the technology shocks affecting capital production and explore how changes in uncertainty affect equilibrium characteristics. ${ }^{1}$ This setting is useful for several reasons. First, the impact of uncertainty on investment via the lending channel is fairly transparent so that economic intuition is enhanced. Second, the economic environment is a variant of a typical real business cycle model so that key parameters can be calibrated to the data. Third, we demonstrate that linearization solution methods can be employed yet this does not eliminate the influence of second moments on equilibrium. That is, in solving for the linear equilibrium policy functions, the vector of state variables includes the variance of technology shocks buffeting the capital production sector. Another methodological reason to study the implications of this class of models has been recently forwarded by Christiano and Davis (2006) and Justiniano and Primiceri (2006). In these papers, they argue that the Euler equation associated with investment as characterized within the Carlstrom and Fuerst (1997) model may be an important source of business cycle volatility.

The main results can be summarized as follows. In contrast to an aggregate technology shock that affects investment demand, we show that an increase in uncertainty results in a shift in the investment supply schedule. In particular, an increase in uncertainty will cause an increase in the price of capital and a fall in investment activity. Another important result is that time-varying uncertainty produces countercyclical bankruptcy rates. In contrast, Carlstrom and Fuerst's (1997) analysis of aggregate technology shocks produced the counterfactual prediction of procyclical bankruptcy rates.

On a less positive note, we also demonstrate that the quantitative magnitude of these effects is small relative to that of an aggregate technology shock. While this result argues against the importance of second moment effects, we think it is premature to eliminate changes in uncertainty as an important impulse mechanism to the economy. The credit channel model we examine has a sufficiently simple structure so that linearization methods can be employed to analyse second moments; it is quite possible, however, that this structure is precisely why uncertainty does not play a critical quantitative role. ${ }^{2}$ Moreover, Bloom (2007) has

\footnotetext{
${ }^{1}$ Our choice of model and analysis of shocks to second moments is similar to that in Christiano et al. (2003) in which they examined the role that uncertainty and several other factors played in the Great Depression. Given their interest in the particular historical episode, they did not examine in detail the role that uncertainty plays in a credit channel model.

${ }^{2}$ In general, the basic RBC model exhibits a high degree of linearity (see Aruoba et al., 2006)) so the quantitative importance of second moment shocks is an open question. Again,

(C) 2008 The Authors. Journal compilation (C) 2008 Blackwell Publishing Ltd and the Board of Trustees of the Bulletin of Economic Research.
} 
recently studied the effects of uncertainty due to rare events like the terrorist attack experienced on 9/11. In the model studied here, these large shocks would indeed have quantitatively important implications. We see our efforts as primarily pedagogical and argue that richer (e.g., non-linear) environments and more sophisticated numerical methods will be needed to fully explore the role of time-varying uncertainty.

\section{MODEL}

We employ the agency cost business cycle model of Carlstrom and Fuerst (1997) to address the financial intermediaries' role in the propagation of productivity shocks and extend their analysis by introducing timevarying uncertainty. Since, for the most part, the model is identical to that in Carlstrom and Fuerst, the exposition of the model will be brief with primary focus on the lending channel. A full presentation of the model is given in the Appendix.

The model is a variant of a standard RBC model in which an additional production sector is added. This sector produces capital using a technology that transforms investment into capital. In a standard RBC framework, this conversion is always one-to-one; in the Carlstrom and Fuerst framework, the production technology is subject to technology shocks. (The aggregate production technology is also subject to technology shocks as is standard.) This capital production sector is owned by entrepreneurs who finance their production via loans from a risk-neutral financial intermediation sector - this lending channel is characterized by a loan contract with a fixed interest rate. (Both capital production and the loans are intra-period.) If a capital-producing firm realizes a low technology shock, it will declare bankruptcy and the financial intermediary will take over production; this activity is subject to monitoring costs.

The timing of events is as follows:

1. The exogenous state vector of technology shocks and uncertainty shocks, denoted $\left(\theta_{t}, \sigma_{\omega, t}\right)$, is realized.

2. Firms hire inputs of labour and capital from households and entrepreneurs and produce output via an aggregate production function.

3. Households make their labour, consumption and savings/investment decisions. The household transfers $q_{t}$ consumption goods to the banking sector for each unit of investment.

4. With the savings resources from households, the banking sector provides loans to entrepreneurs' via the optimal financial contract.

Bloom (2007) has demonstrated that second moment shocks can have quantitatively important effects.

(C) 2008 The Authors. Journal compilation (C) 2008 Blackwell Publishing Ltd and the Board of Trustees of the Bulletin of Economic Research. 


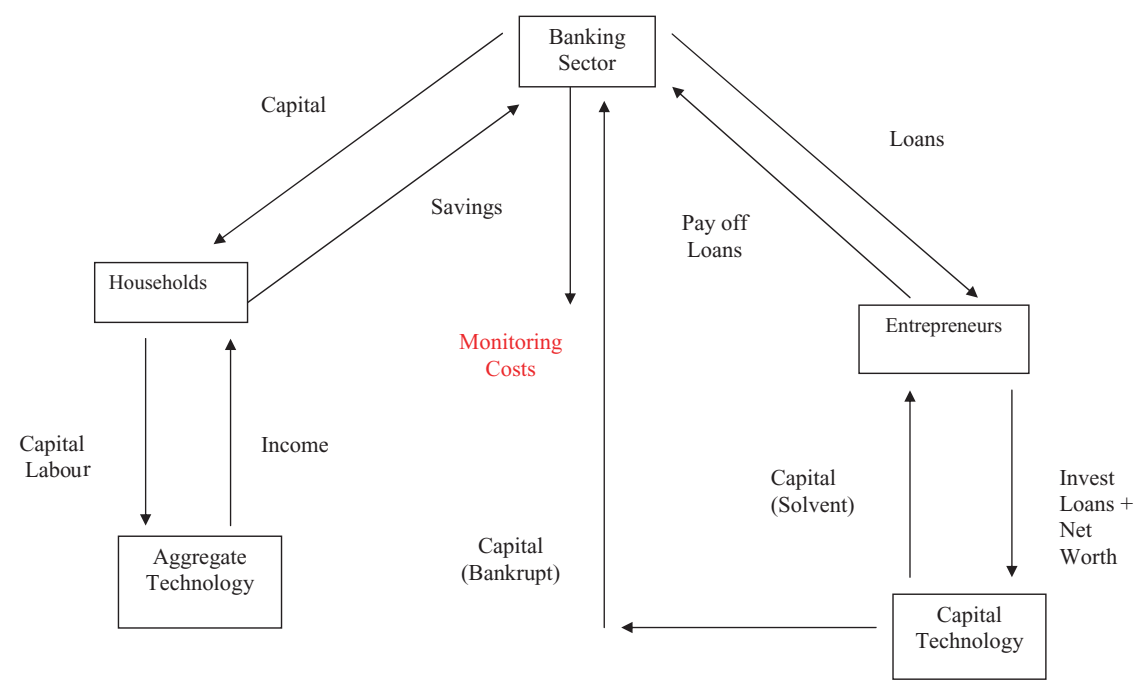

Fig. 1. Flow of funds in credit channel model.

The contract is defined by the size of the loan $\left(i_{t}\right)$ and a cutoff level of productivity for the entrepreneurs' technology shock, $\bar{\omega}_{t}$.

5. Entrepreneurs use their net worth and loans from the banking sector as inputs into their capital-creation technology.

6. The idiosyncratic technology shock of each entrepreneur is realized. If $\omega_{j, t} \geq \bar{\omega}_{t}$ the entrepreneur is solvent and the loan from the bank is repaid; otherwise the entrepreneur declares bankruptcy and production is monitored by the bank at a cost of $\mu i_{t}$.

7. Entrepreneurs that are solvent make consumption choices; these in part determine their net worth for the next period.

A schematic of the implied flows is presented in Figure 1 and a complete description of the economy is given in the Appendix. We now focus on the lending contract and the role of time-varying uncertainty.

\section{II.1 Optimal financial contract}

The optimal financial contract between entrepreneur and the Capital Mutual Fund is described by Carlstrom and Fuerst (1997). But for expository purposes as well as to explain our approach in addressing the second moment effect on equilibrium conditions, we briefly outline the model. In deriving the optimal contract, both entrepreneurs and lenders take the price of capital, $q$, and net worth, $n$, as given.

The entrepreneur has access to a stochastic technology that transforms $i_{t}$ units of consumption into $\omega_{t} i_{t}$ units of capital. In Carlstrom and Fuerst (1997), the technology shock $\omega_{t}$ was assumed to be distributed as i.i.d.

(C) 2008 The Authors. Journal compilation (C) 2008 Blackwell Publishing Ltd and the Board of Trustees of the Bulletin of Economic Research. 
with $E\left(\omega_{t}\right)=1$. While we maintain the assumption of constant mean, we assume that the standard deviation is time-varying. Specifically, we assume that the standard deviation of the capital production technology shock is governed by the following AR(1) process.

$$
\sigma_{\omega, t}=\bar{\sigma}_{\omega}^{1-\zeta} \sigma_{\omega, t-1}^{\zeta} u_{t}
$$

where $\zeta \in(0,1)$ and $u_{t} \sim$ i.i.d with a mean of unity. ${ }^{3}$ The unconditional mean of the standard deviation is given by $\bar{\sigma}_{\omega}$. The realization of $\omega_{t}$ is privately observed by the entrepreneur-banks can observe the realization at a cost of $\mu i_{t}$ units of consumption.

The entrepreneur enters period $t$ with one unit of labour endowment and $z_{t}$ units of capital. Labour is supplied inelastically while capital is rented to firms; hence income in the period is $w_{t}+r_{t} z_{t}$. This income along with remaining capital determines net worth (denoted as $n_{t}$ and denominated in units of consumption) at time $t$ :

$$
n_{t}=w_{t}+z_{t}\left(r_{t}+q_{t}(1-\delta)\right)
$$

With a positive net worth, the entrepreneur borrows $i_{t}-n_{t}$ consumption goods and agrees to pay back $\left(1+r^{k}\right)\left(i_{t}-n_{t}\right)$ capital goods to the lender, where $r^{k}$ is the interest rate on loans. Thus, the entrepreneur defaults on the loan if his realization of output is less then the re-payment, i.e.,

$$
\omega_{t}<\frac{\left(1+r^{k}\right)\left(i_{t}-n_{t}\right)}{i_{t}} \equiv \bar{\omega}_{t}
$$

The optimal borrowing contract is given by the pair $\left(i_{t}, \bar{\omega}_{t}\right)$ that maximizes the entrepreneur's return subject to the lender's willingness to participate (all rents go to the entrepreneur). Denoting the c.d.f. and p.d.f. of $\omega_{t}$ as $\Phi\left(\omega_{t} ; \sigma_{\omega, t}\right)$ and $\phi\left(\omega_{t} ; \sigma_{\omega, t}\right)$ respectively, the contract is determined by the solution to ${ }^{4}$

$$
\max _{\{i, \bar{\omega}\}} q i_{t} f\left(\bar{\omega}_{t} ; \sigma_{\omega, t}\right) \text { subject to } q i_{t} g\left(\bar{\omega}_{t} ; \sigma_{\omega, t}\right) \geq i-n
$$

where

$$
f\left(\bar{\omega}_{t} ; \sigma_{\omega, t}\right)=\int_{\bar{\omega}_{t}}^{\infty} \omega \phi\left(\omega ; \sigma_{\omega, t}\right) \mathrm{d} \omega-\left[1-\Phi\left(\bar{\omega}_{t} ; \sigma_{\omega, t}\right)\right] \bar{\omega}_{t}
$$

\footnotetext{
${ }^{3}$ This autoregressive process is used so that, when the model is log-linearized, $\hat{\sigma}_{\omega, t}$ (defined as the percentage deviations from $\bar{\sigma}_{\omega}$ ) follows a standard, mean-zero AR(1) process.

${ }^{4}$ The notation $\Phi\left(\omega ; \sigma_{\omega, t}\right)$ is used to denote that the distribution function is time-varying as determined by the realization of the random variable, $\sigma_{\omega, t}$. For expositional purposes, we suppress the time notation on the price of capital and net worth since these are treated as parameters in this section.

(C) 2008 The Authors. Journal compilation (C) 2008 Blackwell Publishing Ltd and the Board of Trustees of the Bulletin of Economic Research.
} 
which can be interpreted as the fraction of the expected net capital output received by the entrepreneur,

$$
\begin{aligned}
g\left(\bar{\omega}_{t} ; \sigma_{\omega, t}\right)= & \int_{-\infty}^{\bar{\omega}_{t}} \omega \phi\left(\omega ; \sigma_{\omega, t}\right) \mathrm{d} \omega \\
& +\left[1-\Phi\left(\bar{\omega}_{t} ; \sigma_{\omega, t}\right)\right] \bar{\omega}_{t}-\Phi\left(\bar{\omega}_{t} ; \sigma_{\omega, t}\right) \mu
\end{aligned}
$$

which represents the lender's fraction of expected capital output; $\Phi\left(\bar{\omega}_{t} ; \sigma_{\omega, t}\right)$ is the bankruptcy rate. Also note that $f\left(\bar{\omega}_{t} ; \sigma_{\omega, t}\right)+$ $g\left(\bar{\omega}_{t} ; \sigma_{\omega, t}\right)=1-\Phi\left(\bar{\omega}_{t} ; \sigma_{\omega, t}\right) \mu$ : the right-hand side is the average amount of capital that is produced. This is split between entrepreneurs and lenders while monitoring costs reduce net capital production.

The necessary conditions for the optimal contract problem are

$$
\frac{\partial(.)}{\partial \bar{\omega}}: q i f^{\prime}(\bar{\omega})=-\lambda q i \frac{\partial g\left(\bar{\omega}_{t} ; \sigma_{\omega, t}\right)}{\partial \bar{\omega}}
$$

where $\lambda_{t}$ is the shadow price of the entrepreneur's resources. Using the definitions of $f\left(\bar{\omega}_{t} ; \sigma_{\omega, t}\right)$ and $g\left(\bar{\omega}_{t} ; \sigma_{\omega, t}\right)$, this can be rewritten as

$$
1-\frac{1}{\lambda_{t}}=\frac{\phi\left(\bar{\omega}_{t} ; \sigma_{\omega, t}\right)}{1-\Phi\left(\bar{\omega}_{t} ; \sigma_{\omega, t}\right)} \mu
$$

As shown by Equation (4), the shadow price of the resources used in lending is an increasing function of the relevant inverse Mill's ratio (interpreted as the conditional probability of bankruptcy) and the agency costs. If the product of these terms equals zero, then the shadow price equals the cost of capital production, i.e., $\lambda_{t}=1$.

The second necessary condition is

$$
\frac{\partial(.)}{\partial i_{t}}: q f\left(\bar{\omega}_{t} ; \sigma_{\omega, t}\right)=-\lambda_{t}\left[1-q g\left(\bar{\omega}_{t} ; \sigma_{\omega, t}\right)\right]
$$

Solving for $q$ using the first-order conditions, we have

$$
\begin{aligned}
q^{-1} & =\left[\left(f\left(\bar{\omega}_{t} ; \sigma_{\omega, t}\right)+g\left(\bar{\omega}_{t} ; \sigma_{\omega, t}\right)\right)+\frac{\phi\left(\bar{\omega}_{t} ; \sigma_{\omega, t}\right) \mu f\left(\bar{\omega}_{t} ; \sigma_{\omega, t}\right)}{\partial f\left(\bar{\omega}_{t} ; \sigma_{\omega, t}\right) / \partial \bar{\omega}}\right] \\
& =\left[1-\Phi\left(\bar{\omega}_{t} ; \sigma_{\omega, t}\right) \mu+\frac{\phi\left(\bar{\omega}_{t} ; \sigma_{\omega, t}\right) \mu f\left(\bar{\omega}_{t} ; \sigma_{\omega, t}\right)}{\partial f\left(\bar{\omega}_{t} ; \sigma_{\omega, t}\right) / \partial \bar{\omega}}\right] \\
& \equiv\left[1-D\left(\bar{\omega}_{t}, \sigma_{\omega, t}\right)\right]=F\left(\bar{\omega}_{t}, \sigma_{\omega, t}\right)
\end{aligned}
$$

where $D\left(\bar{\omega}_{t} ; \sigma_{\omega, t}\right)$ can be thought of as the total default costs.

It is straightforward to show that Equation (5) defines an implicit function $\bar{\omega}\left(q, \sigma_{\omega, t}\right)$ that is increasing in $q$. Also note that, in equilibrium, 


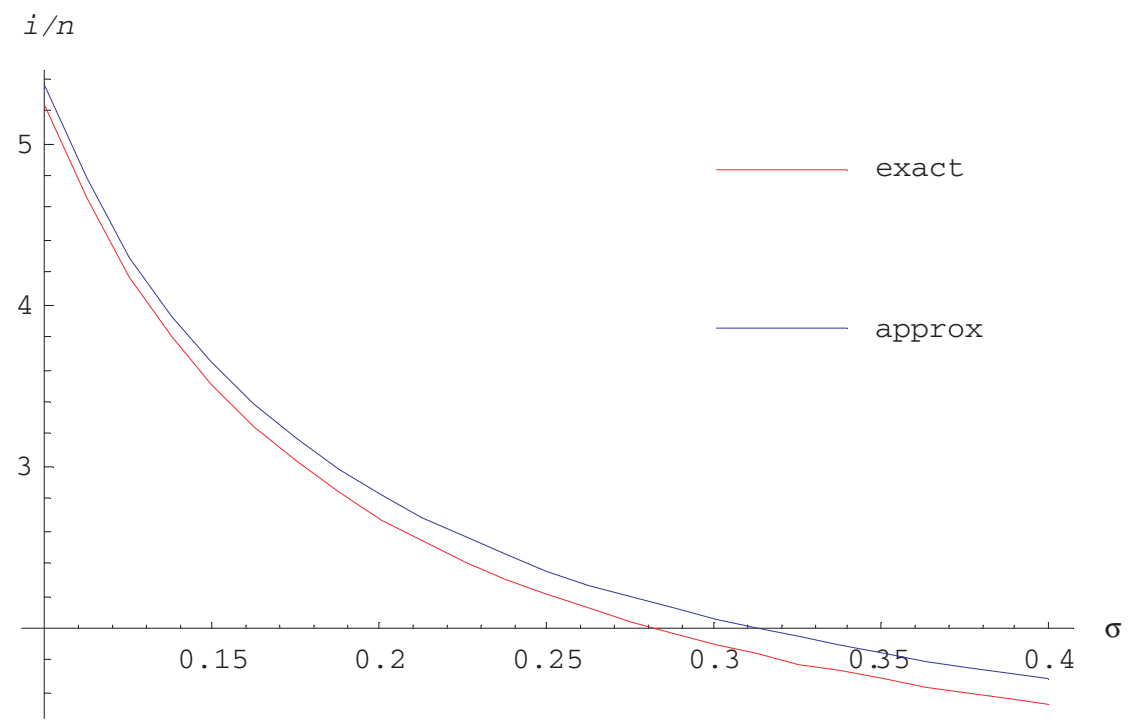

Fig. 2. Exact and approximate behaviour of $i / n$ as a function of $\sigma$

the price of capital, $q$, differs from unity due to the presence of the credit market frictions. (Note that $\partial f\left(\bar{\omega}_{t} ; \sigma_{\omega, t}\right) / \partial \bar{\omega}=\Phi\left(\bar{\omega}_{t} ; \sigma_{\omega, t}\right)-1<0$.)

The incentive compatibility constraint implies

$$
i_{t}=\frac{1}{1-q g\left(\bar{\omega}_{t} ; \sigma_{\omega, t}\right)} n
$$

Equation (6) implies that investment is linear in net worth and defines a function that represents the amount of consumption goods placed in to the capital technology: $i\left(q, n, \sigma_{\omega, t}\right)$. The fact that the function is linear implies that the aggregate investment function is well defined.

The effect of an increase in uncertainty on investment in this model can be understood by first turning to Equation (5). Under the assumption that the price of capital is unchanged, this implies that the costs of default, represented in the function $D\left(\bar{\omega}_{t}, \sigma_{\omega, t}\right)$, must also be unchanged. With a mean-preserving spread in the distribution for $\omega_{t}$, this implies that $\bar{\omega}_{t}$ will fall. As a consequence, the lenders' expected capital return, $g\left(\bar{\omega}_{t} ; \sigma_{\omega, t}\right)$, will also fall since, as shown in the Appendix, $g\left(\bar{\omega}_{t} ; \sigma_{\omega, t}\right) \approx \bar{\omega}_{t}$. Given the incentive compatibility constraint

$$
q i_{t} g\left(\bar{\omega}_{t} ; \sigma_{\omega, t}\right)=i_{t}-n
$$

the fall in the left-hand side induces a fall in $i_{t}$. This relationship is shown numerically (using the parameter values described in the next section) in Figure 2.

The effects of the two technology shocks, the aggregate technology shock $\theta_{t}$ and the uncertainty shock $\sigma_{\omega, t}$, on the capital market can 


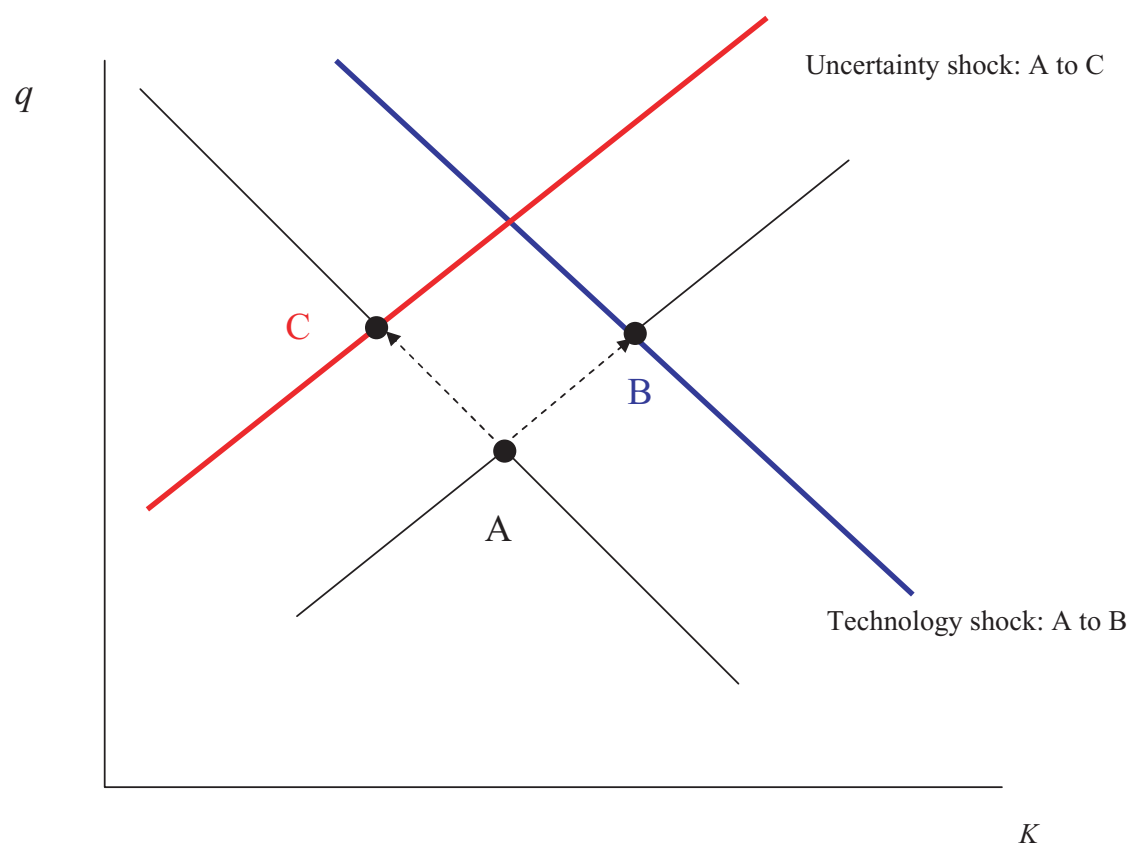

Fig. 3. Technology and uncertainty shocks: effects on investment demand and supply.

be summarized graphically as shown in Figure 3. While not analysed explicitly here, an aggregate technology shock shifts the location of the capital demand curve as both the income effect and, if shocks are positively autocorrelated, the substitution effect of higher expected marginal productivity of capital causes the demand curve to shift outward for a positive technology shock. This will, ceteris paribus, cause the price of capital to increase; note this explains the procyclical bankruptcy rates in Carlstrom and Fuerst (1997) given that $\partial \bar{\omega} / \partial q>0$ as mentioned previously. In contrast, an increase in uncertainty causes the investment supply function to shift leftward resulting in a higher price of capital but smaller quantity of investment. These partial equilibrium results are not overturned in the general equilibrium setup.

\section{II.2 Equilibrium}

Equilibrium in the economy is represented by market clearing in four markets: the labour markets for households and entrepreneurs and the goods markets for consumption and capital. Letting $\left(H_{t}, H_{t}^{e}\right)$ denote the aggregate labour supply of, respectively, households and entrepreneurs, 
we have

$$
H_{t}=(1-\eta) l_{t}
$$

where $l_{t}$ denotes labour supply of households and $\eta$ denotes the fraction of entrepreneurs in the economy.

$$
H_{t}^{e}=\eta
$$

Goods market equilibrium is represented by

$$
C_{t}+I_{t}=Y_{t}
$$

where $C_{t}=(1-\eta) c_{t}+\eta c_{t}^{e}$ and $I_{t}=\eta i_{t}$. (Note upper case variables denote aggregate quantities while lower case denote per-capita quantities.)

The law of motion of aggregate capital is given by

$$
K_{t+1}=(1-\delta) K_{t}+I_{t}\left[1-\Phi\left(\bar{\omega}_{t} ; \sigma_{\omega, t}\right) \mu\right]
$$

A competitive equilibrium is defined by the decision rules for aggregate capital, entrepreneur's capital, household labour, entrepreneur's labour, the price of capital, entrepreneur's net worth, investment, the cutoff productivity level, household consumption and entrepreneur's consumption given by the vector $\left\{K_{t+1}, Z_{t+1}, H_{t}, H_{t}^{e}, q_{t}, n_{t}, i_{t}, \bar{\omega}_{t}, c_{t}, c_{t}^{e}\right\}$ where these decision rules are stationary functions of $\left\{K_{t}, Z_{t}, \theta_{t}, \sigma_{\omega, t}\right\}$ and satisfy the following equations: ${ }^{5}$

$$
\begin{gathered}
\nu c_{t}=\alpha_{H} \frac{Y_{t}}{H_{t}} \\
\frac{q_{t}}{c_{t}}=\beta E_{t}\left\{\frac{1}{c_{t+1}}\left(q_{t+1}(1-\delta)+\alpha_{K} \frac{Y_{t+1}}{K_{t+1}}\right)\right\} \\
q_{t}=\left\{1-\Phi\left(\bar{\omega} ; \sigma_{\omega, t}\right) \mu+\frac{\phi\left(\bar{\omega} ; \sigma_{\omega, t}\right) \mu f\left(\bar{\omega} ; \sigma_{\omega, t}\right)}{f^{\prime}\left(\bar{\omega}_{t}\right)}\right\}^{-1} \\
q_{t}=\beta \gamma E_{t}\left\{\left(q_{t+1}(1-\delta)+\alpha_{K} \frac{Y_{t+1}}{K_{t+1}}\right)\left(\frac{q_{t+1} f\left(\bar{\omega} ; \sigma_{\omega, t}\right)}{1-q_{t+1} g\left(\bar{\omega} ; \sigma_{\omega, t}\right)}\right)\right\} \\
n_{t}=\alpha_{H^{e}} \frac{Y_{t}}{H_{t}^{e}}+Z_{t}\left(q_{t}(1-\delta)+\alpha_{K} \frac{Y_{t}}{K_{t}}\right)
\end{gathered}
$$

${ }^{5}$ A more thorough presentation of the equilibrium conditions is presented in the Appendix. (C) 2008 The Authors. Journal compilation (C) 2008 Blackwell Publishing Ltd and the Board of Trustees of the Bulletin of Economic Research. 


$$
\begin{gathered}
Z_{t+1}=\eta n_{t}\left\{\frac{f\left(\bar{\omega} ; \sigma_{\omega, t}\right)}{1-q_{t} g\left(\bar{\omega} ; \sigma_{\omega, t}\right)}\right\}-\eta \frac{c_{t}^{e}}{q_{t}} \\
\theta_{t+1}=\theta_{t}^{\rho} \xi_{t+1} \text { where } \xi_{t} \sim \text { i.i.d. with } E\left(\xi_{t}\right)=1 \\
\sigma_{\omega, t+1}=\bar{\sigma}_{\omega}^{1-\zeta} \sigma_{\omega, t}^{\zeta} u_{t+1} \text { where } u_{t} \sim \text { i.i.d. with } E\left(u_{t}\right)=1
\end{gathered}
$$

The first equation represents the labour-leisure choice for households while the second equation is the necessary condition associated with households' savings decision. The third and fourth equations are from the optimal lending contract while the fifth equation is the necessary condition associated with the entrepreneur's savings decision. The sixth equation is the determination of net worth while the seventh gives the evolution of the entrepreneur's capital. (The evolution of aggregate capital is given in Equation (10).) The final two equations represent the laws of motion for the aggregate technology and uncertainty shock, respectively.

\section{EQUILIBRIUM CHARACTERISTICS}

\section{III.1 Steady-state analysis}

While our focus is primarily on the cyclical behaviour of the economy, an examination of the steady-state properties of the economy is useful for two reasons. First, by studying the interaction between uncertainty (i.e., the variance of the technology shock affecting the capital production sector) and the steady state, the intuition for how time-varying uncertainty affects the cyclical characteristics of the economy is improved. Second, it is important to point out that changes in the second moment of technology shocks affect the level of the economy - most notably consumption and output. That is, since the cyclical analysis presented in the next section is characterized in terms of deviations from steady state, the impact of changes in uncertainty on the level of economic activity is lost. $^{6}$

For this analysis, we use, to a large extent, the parameters employed in Carlstrom and Fuerst's (1997) analysis. Specifically, the parameter values given in Table 1 are used. Agent's discount factor, the depreciation rate and capital's share are fairly standard in RBC analysis. The remaining parameter, $\mu$, represents the monitoring costs associated with bankruptcy.

\footnotetext{
${ }^{6}$ This statement is in reference to Lucas's analysis of the cost of business cycles (Lucas 1987) in which the trend and cycle are treated as distinct. In contrast, our analysis demonstrates that the cyclical behaviour of the economy has implications for the level of the steady state. If one were using an endogenous growth model, cyclical behaviour may well have implications for the trend.

(C) 2008 The Authors. Journal compilation (C) 2008 Blackwell Publishing Ltd and the Board of Trustees of the Bulletin of Economic Research.
} 
TABLE 1

Parameter values

\begin{tabular}{lccc}
\hline$\beta$ & $\alpha$ & $\delta$ & $\mu$ \\
0.99 & 0.36 & 0.02 & 0.25 \\
\hline
\end{tabular}

TABLE 2

Parameter values

\begin{tabular}{lccc}
\hline Economy & $\sigma$ & $r p$ & $\gamma$ \\
\hline $\begin{array}{l}\text { Economy I } \\
\text { (Carlstrom and Fuerst) }\end{array}$ & 0.207 & $0.467 \%$ & 0.9474 \\
Economy II & 0.30 & $0.605 \%$ & 0.954 \\
\hline
\end{tabular}

This value, as noted by Carlstrom and Fuerst (1997), is relatively prudent given estimates of bankruptcy costs (which range from 20 percent (Altman, 1984) to 36 percent (Alderson and Betker, 1995) of firm assets).

The remaining parameters, $\sigma, \gamma$, determine the steady-state bankruptcy rate (which we denote as $b r$ and is expressed in percentage terms as a quarterly rate) and the risk premium (denoted $r p$ and again expressed as a quarterly rate) associated with bank loans. ${ }^{7}$ (Also, as described in the Appendix, especially see Equation (35), the parameter $\gamma$ is introduced so that entrepreneurs discount the future at a greater rate than households. This is to ensure that entrepreneurs do not selffinance their investment projects.) To examine the role of uncertainty on the steady-state behaviour of the economy, we hold the bankruptcy rate constant to that studied in Carlstrom and Fuerst and increase the standard deviation by slightly less than 50 percent; the implied values for $\gamma$ and the risk premium are given in Table $2 .{ }^{8}$

The effect of greater uncertainty in the capital production sector is seen in Table 3. (All values in Table 3 are percentage changes relative to the Carlstrom and Fuerst economy.) Consistent with the partial equilibrium analysis presented earlier, a mean-preserving spread in the entrepreneur's technology shock causes the price of capital to increase and steady-state capital to fall. This also implies a decrease in consumption, a slight increase in steady-state labour, and a fall in steady-state output.

\footnotetext{
${ }^{7}$ The fraction of entrepreneurs in the economy, $\eta$, is not a critical parameter for the behaviour of the economy. As Carlstrom and Fuerst note, it is simply a normalization. Aggregate consumption in the model is indeed a weighted average of household and entrepreneurial consumption but the weights are determined by the steady-state level of per-capita consumption for these groups. This is endogenously determined - but not by $\eta$. This is demonstrated at the end of the Appendix.

${ }^{8}$ As discussed in Carlstrom and Fuerst, a bankruptcy rate of 0.974 percent (per quarter) and an annual risk premium of 187 basis points are broadly consistent with the US data. 
TABLE 3

Steady-State effects of greater uncertainty (comparison to Carlstrom and Fuerst economy)

\begin{tabular}{lc}
\hline Variable & Economy II \\
\hline$c$ & -0.19 \\
$k$ & -0.51 \\
$h$ & 0.04 \\
$y$ & -0.16 \\
$q$ & 0.35 \\
$z$ & 28.4 \\
$n$ & 28.7 \\
\hline
\end{tabular}

\section{III.2 Cyclical behaviour}

As described in Section II, Equations (11) through (19) determine the equilibrium properties of the economy. To analyse the cyclical properties of the economy, we linearize (i.e., take a first-order Taylor series expansion of) these equations around the steady-state values and express all terms as percentage deviations from steady-state values. This numerical approximation method is standard in quantitative macroeconomics. What is not standard in this model is that the second moment of technology shocks hitting the capital production sector will influence equilibrium behaviour and, therefore, the equilibrium policy rules. That is, linearizing the equilibrium conditions around the steady state typically imposes certainty equivalence so that variances do not matter. In this model, however, the variance of the technology shock can be treated as an additional state variable through its role in determining lending activities and, in particular, the nature of the lending contract. ${ }^{9}$ Linearizing the system of equilibrium conditions does not eliminate that role in this economy and hence we think that this is an attractive feature of the model.

While the previous section analysed the steady-state behaviour of four different economies, in this section we employ the same parameters as in the Carlstrom and Fuerst model (economy I in the previous section). We depart from Carlstrom and Fuerst by relaxing the i.i.d. assumption for the capital sector technology shock. This is reflected in the law of motion for the standard deviation of the technology shock which is given in Equation (19); for convenience this is rewritten below:

$$
\sigma_{\omega, t+1}=\bar{\sigma}_{\omega}^{1-\zeta} \sigma_{\omega, t}^{\zeta} u_{t+1}
$$

\footnotetext{
${ }^{9}$ Specifically, $\omega_{t}$ is assumed to be $\log$ normally distributed. Hence, the linear approximation to the equations describing the financial contract (Equations (24) and (25)) will include the second moment of $\omega_{t}$.

(C) 2008 The Authors. Journal compilation (C) 2008 Blackwell Publishing Ltd and the Board of Trustees of the Bulletin of Economic Research.
} 
As in Carlstrom and Fuerst, the standard deviation of the technology shock $\omega_{t}$ is, on average, equal to 0.207 . That is, we set $\bar{\sigma}_{\omega}=0.207$. We then examine two different economies characterized by the persistence in uncertainty, i.e., the parameter $\zeta$. In the low persistence economy we set $\zeta=0.05$, while in the moderate persistence economy we set $\zeta=$ 0.90 . The behaviour of these two economies is analysed by examining the impulse response functions of several key variables to a 1 percent innovation in $\sigma_{\omega}$. These are presented in Figures 4-6.

We first turn to aggregate output and household consumption and investment. With greater uncertainty, the bankruptcy rate increases in the economy (this is verified in Figure 5), which implies that agency costs increase. The rate of return on investment for the economy therefore falls. Households, in response, reduce investment and increase consumption and leisure. The latter response causes output to fall. Note that the consumption and leisure response is increasing in the degree of persistence. This is not the case, however, for investment - this is due to the increase in the price of capital (see Figure 5) and reflects the behaviour of entrepreneurs. This behaviour is understood after first examining the lending channel.

The increase in uncertainty affects, predictably, all three key variables in the lending channel: the price of capital, the risk premium associated with loans and the bankruptcy rate. As already mentioned, the bankruptcy rate increases and, in the high persistence economy, this increased rate of bankruptcy lasts for several quarters. This result implies that the bankruptcy rate is countercyclical in this economy; in contrast, in the analysis by Carlstrom and Fuerst the bankruptcy rate was, counterfactually, procyclical. ${ }^{10}$ Their focus was on the effects of innovation to the aggregate technology shock and, because of the assumed persistence in this shock, is driven by the change in the first moment of the aggregate production shock. Our analysis demonstrates that second moment effects may play a significant role in these correlations over the business cycle. Further research, both empirical and theoretical, in this area would be fruitful. Returning to the model, the increased bankruptcy rate implies that the price of capital is greater and this increase lasts longer in the high persistence economy. The same is true for the risk premium on loans.

Figure 6 reports the consumption and net worth of entrepreneurs in the economies. In contrast to all other variables, persistence has a dramatic qualitative effect on entrepreneurs' behaviour. With low persistence, entrepreneurs exploit the high price of capital to increase consumption:

\footnotetext{
${ }^{10}$ In the Carlstrom and Fuerst (1997) model, a technology shock increases output and the demand for capital. The resulting increase in the price of capital implies greater lending activity and, hence, an increase in the bankruptcy rate (and risk premia). Here, greater uncertainty results in greater bankruptcy rates even though investment falls; since labour is also reduced, this produces countercyclical bankruptcy rates and risk premia.

(C) 2008 The Authors. Journal compilation (C) 2008 Blackwell Publishing Ltd and the Board of Trustees of the Bulletin of Economic Research.
} 

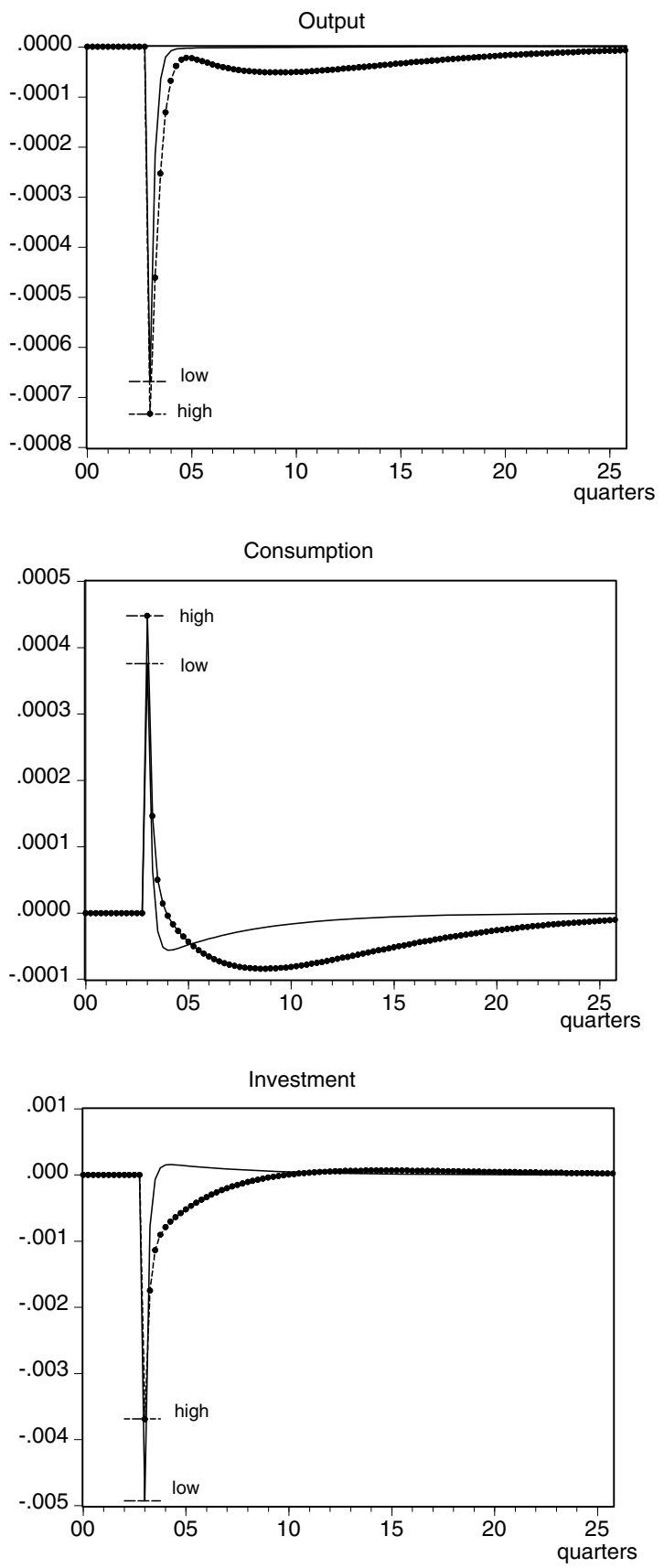

Fig. 4. Response of output, consumption and investment to a 1 percent increase in uncertainty in low and high persistence economies (percentage deviations from steady-state values).

(C) 2008 The Authors. Journal compilation (C) 2008 Blackwell Publishing Ltd and the Board of Trustees of the Bulletin of Economic Research. 

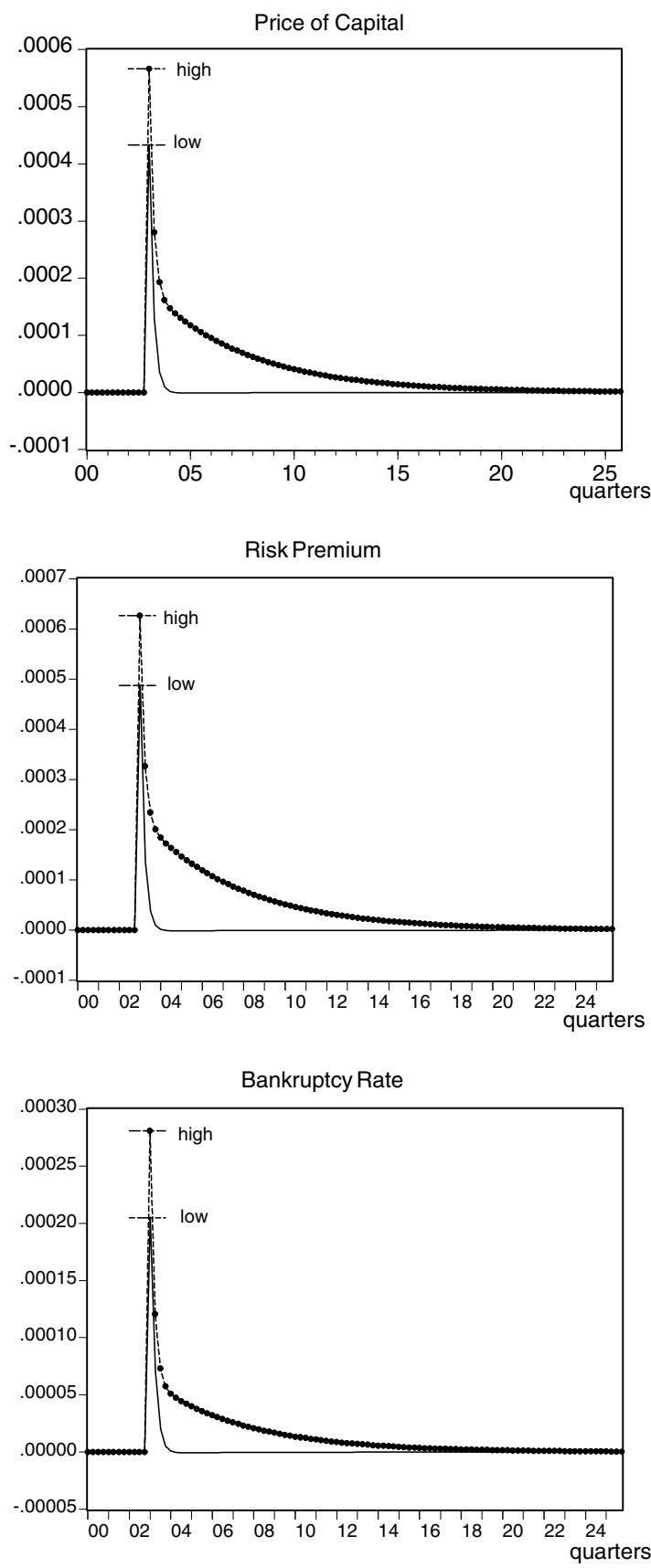

Fig. 5. Response of price of capital, risk premia and bankrupty rate to a 1 percent increase in uncertainty in low and high persistence economies (percentage deviations from steady-state values). 

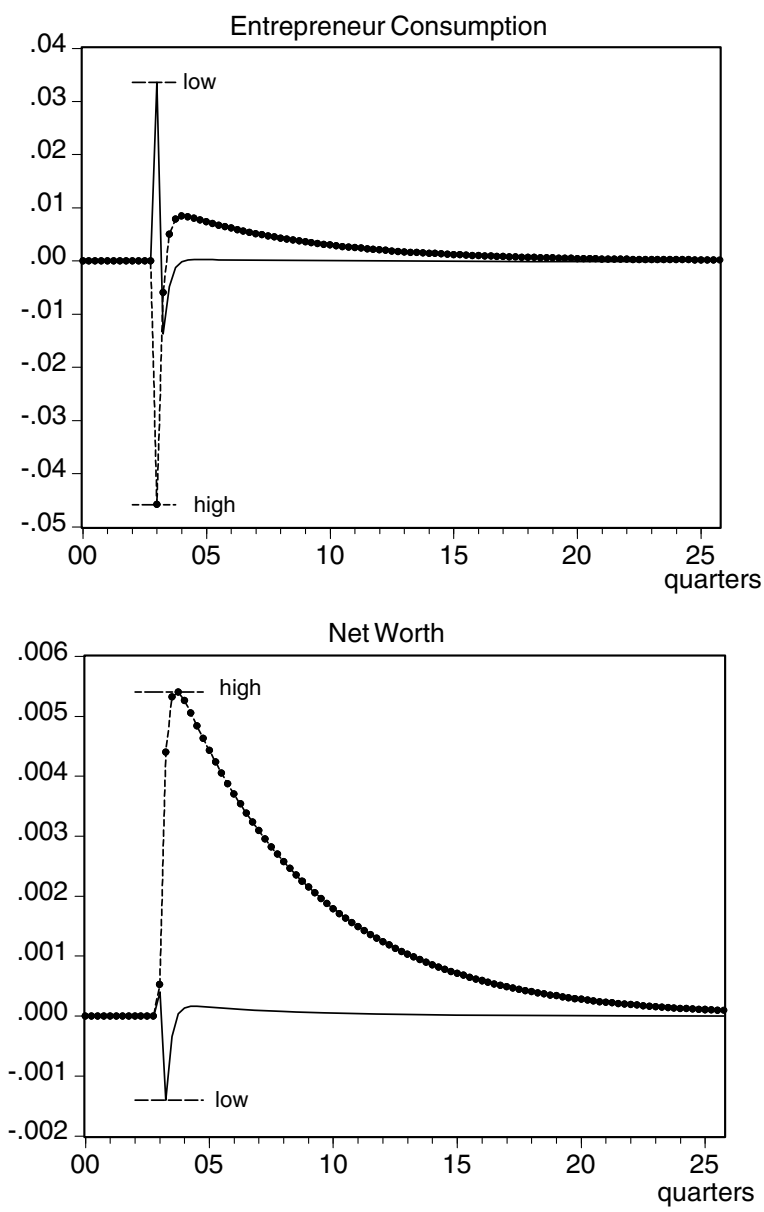

Fig. 6. Response of entrepreneurs' consumption and net worth to a 1 percent increase in uncertainty in low and high persistence economies (percentage deviations from steady-state values).

the lack of persistence provides no incentive to increase investment. Since the price of capital quickly returns to its steady-state values, the increased consumption erodes entrepreneurs' net worth. To restore net worth to its steady-state value, consumption falls temporarily. The behaviour in the high persistence economy is quite different: the price of capital is high and forecast to stay high so investment increases dramatically. Initially, the investment is financed by lower consumption, but as entrepreneurs net worth increases (due to greater capital and a higher price of capital) consumption also increases. This endogenous response by entrepreneurs is why, in the high persistence economy, the 
TABLE 4

Business cycle characteristics ${ }^{\mathrm{a}}$

\begin{tabular}{lcccccccccc}
\hline & & \multicolumn{4}{c}{ Volatility relative to $y$} & \multicolumn{4}{c}{ Correlation with $y$} \\
Shocks & $\sigma_{y}$ & $c$ & $h$ & $i$ & $k$ & $c$ & $h$ & $i$ & $k$ \\
\hline$\theta$ & 0.046 & 0.63 & 0.59 & 2.72 & 0.87 & 0.84 & 0.81 & 0.91 & 0.65 \\
$\sigma_{\omega}$ & 0.0007 & 0.64 & 1.43 & 5.14 & 1.03 & -0.54 & 0.93 & 0.97 & 0.36 \\
& & & & & & & & & \\
US data $^{\mathrm{b}}$ & 1.71 & 0.49 & 0.86 & 3.15 & 0.36 & 0.76 & 0.86 & 0.90 & -0.08
\end{tabular}

${ }^{a}$ For this comparative analysis, the standard deviation of the innovation to both shocks was assumed to be 0.007 . This figure is typical for total factor productivity shocks but whether this is a good figure for shocks to the second moments is an open question. We also assumed that both shocks exhibit high persistence with an autocorrelation of 0.95 for $\theta_{t}$ and 0.90 for $\sigma_{\omega}$.

${ }^{\mathrm{b}}$ The US figures are from Kydland and Prescott (1990).

initial fall in aggregate investment is not as great as in the low persistence economy.

A further analysis of the equilibrium characteristics of the high persistence economy is presented in Table 4 in which a few, key second moments are reported. For comparison, the moments implied by the model when subject to total factor productivity shocks $\left(\theta_{t}\right)$ or information shocks $\left(\sigma_{\omega}\right)$ are given along with the corresponding moments from the US data. Note that, while time-varying uncertainty induces greater volatility in labour, investment and the capital stock, the discrepancy between the moments from the artificial economy and the actual data is not that much different from that arising from a standard RBC model subject to productivity shocks. This behaviour stands in stark contrast to the financial intermediation model of Cooper and Ejarque (2000) in which labour and investment were countercyclical and capital stock volatility was over five times greater than GDP volatility. ${ }^{11}$ Their analysis did not present an explicit model of the financial intermediation sector and our analysis suggests that the endogenous response of this sector to shocks is important and leads to improved performance of the model. The model does imply negative correlation between consumption and investment; hence we reach the same conclusion as Cooper and Ejarque (2000): shocks to uncertainty cannot be the dominant shock in the economy since this correlation is counterfactual to business cycle behaviour. This observation does not, in our opinion, rule out uncertainty as playing a role in business cycle behaviour - it simply cannot be the

\footnotetext{
${ }^{11}$ Cooper and Ejarque (2000) analyze two versions of their model: one in which financial intermediation plays a role in financing both undepreciated and new capital and another in which only new capital (i.e., investment) uses financial intermediaries. The countercyclical behaviour of labour and investment is seen in the first version; however, both models exhibit high volatility of the capital stock.

(C) 2008 The Authors. Journal compilation (C) 2008 Blackwell Publishing Ltd and the Board of Trustees of the Bulletin of Economic Research.
} 
sole or dominant factor. ${ }^{12}$ A second important feature seen in Table 4 is the quantitatively small role that second moment shocks have on the economy; as seen in the first column, a 1 percent innovation to the aggregate technology shock produces volatility in GDP over 60 times larger than that from a comparable shock to the conditional standard deviation.

\section{CONCLUSION}

The effect of uncertainty as characterized by second moment effects has been largely ignored in quantitative macroeconomics due to the numerical approximation methods typically employed during the computational exercise. The analysis presented here uses standard solution methods (i.e., linearizing around the steady state) but exploits features of the Carlstrom and Fuerst (1997) agency cost model of business cycles so that time-varying uncertainty can be analysed. While development of more general solution methods that capture second moments effects is encouraged, we think that the intuitive nature of this model and its standard solution method make it an attractive environment to study the effects of time-varying uncertainty.

Our primary findings fall into four broad categories. First, we demonstrate that uncertainty affects the level of the steady state of the economy so that welfare analysis of uncertainty that focuses entirely on the variability of output (or consumption) will understate the true costs of uncertainty. Second, we demonstrate that time-varying uncertainty results in countercyclical bankruptcy rates - a finding that is consistent with the data and opposite to the result in Carlstrom and Fuerst. Third, we show that persistence of uncertainty affects both quantitatively and qualitatively the behaviour of the economy. Quantitatively, however, the impact of an increase is significantly less than that of an aggregate technology shock. We conclude that further research is needed in (at least) two dimensions: the characterization of uncertainty shocks (i.e., second moments or rare catastrophic events) and the development of richer theoretical models that introduce more non-linearities in the equations defining equilibrium. With regard to measuring uncertainty, Bloom et al. (2007) have taken a first step by examining a fairly broad range of data constructs for volatility and uncertainty; they find that these are strongly countercyclical which would be consistent with the model presented here. Clearly, more work is needed in this dimension.

12 The countercyclical behaviour of consumption is a feature in models, such as Greenwood et al. (2000), in which the impulse mechanism affects the price of investment goods. In Greenwood et al. (2000) they impose investment adjustment costs in order to produce procyclical consumption.

(C) 2008 The Authors. Journal compilation (C) 2008 Blackwell Publishing Ltd and the Board of Trustees of the Bulletin of Economic Research. 


\section{REFERENCES}

Alderson, M. J. and Betker, B. L. (1995). 'Liquidation costs and capital structure', Journal of Financial Economics, 39, pp. 45-69.

Altman, E. (1984). 'A further investigation of the bankruptcy cost question', Journal of Finance, 39, pp. 1067-89.

Aruoba, S. B., Fernández-Villaverde, J. and Rubio-Ramirez, J. (2006). 'Comparing solution methods for dynamic equilibrium economies', Journal of Economic Dynamics and Control, 30, pp. 2477-2508.

Bernanke, B. and Gertler, M. (1989). 'Agency costs, net worth, and business fluctuations', American Economic Review, 79, pp. 14-31.

Bernanke, B. and Gertler, M. (1990). 'Financial fragility and economic performance', Quarterly Journal of Economics, 105, pp. 87-114.

Bernanke, B., Gertler, M. and Gilchrist, S. (1999). 'The financial accelerator in a quantitative business cycle framework', in Taylor, J. B. and Woodford, M. (eds), Handbook of Macroeconomics, Vol. 1, Amsterdam: Elsevier Science.

Bloom, N. (2007). 'The impact of uncertainty shocks', NBER Working Paper 13385.

Bloom, N., Floetotto, M. and Jaimovich, N. (2007). 'Really uncertain business cycles', Working Paper, Stanford Economics Department.

Carlstrom, C. and Fuerst, T. (1997). 'Agency costs, net worth, and business fluctuations: a computable general equilibrium analysis', American Economic Review, 87, pp. 893-910.

Christiano, L. and Davis, J. (2006), 'Two flaws in business cycle accounting', NBER Working Paper No. 12647.

Christiano, L., Motto, R. and Rostagno, M. (2003). 'The great depression and the Friedman-Schwartz hypothesis', Journal of Money, Credit, and Banking, 35, pp. 1119-98

Collard, F. and Juillard, M. (2001). 'A higher-order Taylor expansion approach to simulation of stochastic forward-looking models with an application to a non-linear Phillips curve', Computational Economics, 17, pp. 125-39.

Cooper, R. and Ejarque, J. (2000). 'Financial intermediation and aggregate fluctuations: a quantitative analysis', Macroeconomic Dynamics, 4, pp. 423-47.

Greenwood, J., Hercowitz, Z. and Krusell, P. (1997). 'Long-run implications of investment-specific technological change', American Economic Review, 78, pp. 342-62.

Greenwood, J., Hercowitz, Z. and Krusell, P. (2000). 'The role of investmentspecific technological change in the business cycle', European Economic Review, 44, pp. 91-115.

Justiniano, A. and Primiceri, G. (2006). 'The time varying volatility of macroeconomic fluctuations', Working Paper, Department of Economics, Northwestern University.

Kydland, F. and Prescott, E. C. (1990). 'Business cycles: real facts and a monetary myth', Federal Reserve Bank of Minneapolis Quarterly Review, 14, pp. 3-18.

Lucas, R. E., Jr (1987). Models of Business Cycles, Oxford: Blackwell.

Lucas, R. E., Jr (2000). 'Inflation and welfare', Econometrica, 68(2), pp. 247-74.

Olver, F. W. J. (1997). Asymptotics and Special Functions, Wellesley, MA: A.K. Peters. 
Schmitt-Grohe, S. and Uribe, M. (2005). 'Optimal inflation stabilization in a medium-scale macroeconomic model', NBER Working Paper No. 11854.

Schwert, W. G. (1989). 'Why does stock market volatility change over time?', Journal of Finance, 45, pp. 1115-53.

Sims, C. (2001). 'Second order accurate solution of discrete time dynamic equilibrium models', Working Paper, Department of Economics, Princeton University.

\section{APPENDIX}

The lending channel: approximation analysis

To find a simple analytical formula for investment in the partial equilibrium model described in the text, it is convenient to assume the substitution $\bar{\omega}=\exp \left(\omega_{1}\right)$ in order to use the normal rather than lognormal distribution for the technology shock $\omega_{t}$. Using this permits Equations (5) and (6) to be expressed in the form

$$
\begin{aligned}
\frac{i}{n} & =\left(1-q g_{1}\left(\omega_{1}, \sigma\right)\right)^{-1} \\
\frac{1-q^{-1}}{\mu} & =\text { const }=\Phi_{1}\left(\omega_{1}, \sigma\right)+\exp \left(-\omega_{1}\right) \phi_{1}\left(\omega_{1}, \sigma\right) \frac{f_{1}\left(\omega_{1}, \sigma\right)}{1-\Phi_{1}\left(\omega_{1}, \sigma\right)}
\end{aligned}
$$

where $f_{1}\left(\omega_{1}, \sigma\right)=f(\bar{\omega}, \sigma), g_{1}\left(\omega_{1}, \sigma\right)=g(\bar{\omega}, \sigma)$ and so forth.

We need to find a simple approximation for the equations above. To do that we will use the asymptotic expansion on the large parameter $\left|\omega_{1} / \sigma\right|$ $\gg 1$. Evaluated at steady-state levels, the numerical value of $\omega_{1} / \sigma \approx$ -2.4 and so can be considered as 'large' here since its square appears as an argument of the exponent function. Then we have the following representation of terms in (20), (21) (note that the mean of $\omega_{1}$ has been shifted by $\sigma^{2} / 2$ in order to maintain a mean-preserving spread):

$$
\begin{aligned}
\Phi_{1}\left(\omega_{1}, \sigma\right)= & \frac{1}{\sqrt{2 \pi}} \int_{-\infty}^{\omega_{1} / \sigma+\sigma / 2} \exp \left(-\frac{x^{2}}{2}\right) \mathrm{d} x \\
\approx & \frac{1}{\sqrt{2 \pi}\left|\frac{\omega_{1}}{\sigma}+\frac{\sigma}{2}\right|} \exp \left[-\frac{1}{2}\left(\frac{\omega_{1}}{\sigma}+\frac{\sigma}{2}\right)^{2}\right] \\
f_{1}\left(\omega_{1}, \sigma\right)= & 1-\exp \left(\omega_{1}\right)\left[1-\Phi_{1}\left(\omega_{1}, \sigma\right)\right] \\
& -\frac{1}{\sqrt{2 \pi}} \int_{-\infty}^{\omega_{1} / \sigma} \exp \left[\sigma x-\frac{1}{2}\left(x+\frac{\sigma}{2}\right)^{2}\right] \mathrm{d} x \\
\approx & 1-\exp \left(\omega_{1}\right) \\
g_{1}\left(\omega_{1}, \sigma\right)= & 1-\mu \Phi_{1}\left(\omega_{1}, \sigma\right)-f_{1}\left(\omega_{1}, \sigma\right) \approx \exp \left(\omega_{1}\right)
\end{aligned}
$$


The asymptotic expansion of $\Phi_{1}\left(\omega_{1}, \sigma\right)$ uses the following chain of exact and approximate relations:

$$
\begin{aligned}
\int_{-\infty}^{-X} \exp \left(-\frac{x^{2}}{2}\right) \mathrm{d} x & =\frac{1}{X} \int_{0}^{\infty} \exp \left[-\frac{1}{2}\left(-X-\frac{y}{X}\right)^{2}\right] \mathrm{d} y \\
& =\frac{1}{x} \exp \left(-\frac{X^{2}}{2}\right) \int_{0}^{\infty} \exp \left(-y-\frac{y^{2}}{2 X^{2}}\right) \mathrm{d} y \\
& \approx \frac{1}{x} \exp \left(-\frac{X^{2}}{2}\right) \int_{0}^{\infty} \exp (-y) \mathrm{d} y=\frac{1}{x} \exp \left(-\frac{X^{2}}{2}\right)
\end{aligned}
$$

Here we assume $-X$ to be a large negative number and perform the variable substitution $x=-X-y / X$. Note that neglecting the term $-y^{2} / 2 X^{2}$ in the exponent under the integral produces the zero-order term of an asymptotic series. (For the detailed theory of asymptotic series and its applications see Olver (1997).) The approximation for $f_{1}\left(\omega_{1}, \sigma\right)$ and $g_{1}\left(\omega_{1}, \sigma\right)$ uses the smallness of $\Phi_{1}\left(\omega_{1}, \sigma\right)$, which is equal to the bankruptcy rate $b r \simeq 0.00974$. The last integral term in the expression for $f_{1}\left(\omega_{1}, \sigma\right)$ differs from $\Phi_{1}\left(\omega_{1}, \sigma\right)$ by the factor $\exp (\sigma x)$ under the integral, which is smaller than 1 because the range of integration is negative. So that term is less than $\Phi_{1}\left(\omega_{1}, \sigma\right)$ and can also be neglected

Substituting (22) into (20) and (21) produces

$$
\begin{gathered}
\frac{i}{n}=\left(1-q \exp \left(\omega_{1}\right)\right)^{-1} \\
\frac{1-q^{-1}}{\mu} \approx \frac{\exp \left(-\frac{1}{2}\left(\frac{\omega_{1}}{\sigma}+\frac{\sigma}{2}\right)^{2}\right)}{\sqrt{2 \pi}}\left(\frac{1}{\left|\frac{\omega_{1}}{\sigma}+\frac{\sigma}{2}\right|}+\frac{\exp \left(-\omega_{1}\right)-1}{\sigma}\right)
\end{gathered}
$$

Neglecting the small terms $\sigma^{2} / 4$ and $\left|\frac{\omega_{1}}{\sigma}+\frac{\sigma}{2}\right|^{-1}$ in (24) we can rewrite it in the form

$$
\frac{\sigma}{\omega_{1}} \exp \left(\frac{1}{2}\left(\frac{\omega_{1}}{\sigma}\right)^{2}\right)=\frac{\mu}{\sqrt{2 \pi}\left(1-q^{-1}\right)} \exp \left(-\frac{\omega_{1}}{2}\right) \frac{\exp \left(-\omega_{1}\right)-1}{\omega_{1}}
$$

Taking logs yields

$$
\frac{\omega_{1}}{\sigma}=-\sqrt{2\left(\ln w\left(\omega_{1}\right)+\ln \left|\frac{\omega_{1}}{\sigma}\right|\right)}
$$

where

$$
w\left(\omega_{1}\right)=\frac{\mu}{\sqrt{2 \pi}\left(1-q^{-1}\right)} \exp \left(-\frac{\omega_{1}}{2}\right) \frac{\exp \left(-\omega_{1}\right)-1}{\omega_{1}}
$$


The asymptotic solution of (25) can be obtained through the use of logarithmic precision. For that we can assume $\omega_{1} \simeq \omega_{s}\left(\omega_{s}\right.$ is the constant steady-state value) in the expression for $w\left(\omega_{1}\right)$ and iterate (25) one time

$$
\omega_{1} \approx-c_{\sigma} \sigma
$$

where the constant $c_{\sigma}=\sqrt{2\left(\ln w\left(\omega_{s}\right)+\ln \sqrt{2 \ln w\left(\omega_{s}\right)}\right)}$. Substituting the last formula into (23) we obtain the final relation

$$
\frac{i}{n} \approx\left(1-q \exp \left(-c_{\sigma} \sigma\right)\right)^{-1}
$$

Figure 2 graphs this relationship along with the exact relationship determined via numerical methods (all parameter values are those in economy I). As can be seen, the approximation is quite good.

\section{Model description}

Households The representative household is infinitely lived and has expected utility over consumption $c_{t}$ and leisure $1-l_{t}$ with functional form given by

$$
E_{0} t \sum_{t=0}^{\infty} \beta^{t}\left[\ln \left(c_{t}\right)+\nu\left(1-l_{t}\right)\right]
$$

where $E_{0}$ denotes the conditional expectation operator on time zero information, $\beta \in(0,1), \nu>0$, and $l_{t}$ is time $t$ labour. The household supplies labour, $l_{t}$, and rents its accumulated capital stock, $k_{t}$, to firms at the market clearing real wage $w_{t}$ and rental rate $r_{t}$, respectively, thus earning a total income of $w_{t} l_{t}+r_{t} k_{t}$. The household then purchases consumption good from firms at a price of one (i.e., consumption is the numeraire), and purchases new capital, $i_{t}$, at a price of $q_{t}$. Consequently, the household's budget constraint is

$$
w_{t} l_{t}+r_{t} k_{t} \geq c_{t}+q_{t} i_{t}
$$

The law of motion for households' capital stock is standard

$$
k_{t+1}=(1-\delta) k_{t}+i_{t}
$$

where $\delta \in(0,1)$ is the depreciation rate on capital.

The necessary conditions associated with the maximization problem include the standard labour-leisure condition and the intertemporal efficiency condition associated with investment. Given the functional form for preferences, these are

$$
\begin{gathered}
\nu c_{t}=w_{t} \\
\frac{q_{t}}{c_{t}}=\beta E_{t}\left(\frac{q_{t+1}(1-\delta)+r_{t+1}}{c_{t+1}}\right)
\end{gathered}
$$

(C) 2008 The Authors. Journal compilation (C) 2008 Blackwell Publishing Ltd and the Board of Trustees of the Bulletin of Economic Research. 
Firms. The economy's output is produced by firms using Cobb-Douglas technology ${ }^{13}$

$$
Y_{t}=\theta_{t} K_{t}^{\alpha_{K}} H_{t}^{\alpha_{H}}\left(H_{t}^{e}\right)^{\alpha_{H^{e}}}
$$

where $Y_{t}$ represents the aggregate output, $\theta_{t}$ denotes the aggregate technology shock, $K_{t}$ denotes the aggregate capital stock, $H_{t}$ denotes the aggregate household labour supply, $H_{t}^{e}$ denotes the aggregate supply of entrepreneurial labour, and $\alpha_{K}+\alpha_{H}+\alpha_{H^{e}}=1 .{ }^{14}$

The profit-maximizing representative firm's first-order conditions are given by the factor market's condition that wage and rental rates are equal to their respective marginal productivities:

$$
\begin{gathered}
w_{t}=\alpha_{H} \frac{Y_{t}}{H_{t}} \\
r_{t}=\alpha_{K} \frac{Y_{t}}{K_{t}} \\
w_{t}^{e}=\alpha_{H^{e}} \frac{Y_{t}}{H_{t}^{e}}
\end{gathered}
$$

where $w_{t}^{e}$ denotes the wage rate for entrepreneurial labour.

Entrepreneurs. A risk-neutral representative entrepreneur's course of action is as follows. To finance his project at period $t$, he borrows resources from the Capital Mutual Fund according to an optimal financial contract. The entire borrowed resources, along with his total net worth at period $t$, are then invested into his capital creation project. If the representative entrepreneur is solvent after observing his own technology shock, he then makes his consumption decision; otherwise, he declares bankruptcy and production is monitored (at a cost) by the Capital Mutual Fund.

\section{Entrepreneur's Consumption Choice}

To rule out self-financing by the entrepreneur (i.e., which would eliminate the presence of agency costs), it is assumed that the entrepreneur discounts the future at a faster rate than the household. This is represented

\footnotetext{
${ }^{13}$ Note that we denote aggregate variables with upper case while lower case represents per-capita values. Prices are also lower case.

${ }^{14}$ As in Carlstrom and Fuerst, we assume that the entrepreneur's labour share is small, in particular, $\alpha_{H^{e}}=0.0001$. The inclusion of entrepreneurs' labour in the aggregate production function serves as a technical device so that entrepreneurs' net worth is always positive, even when insolvent. 
by following expected utility function:

$$
E_{0} t \sum_{t=0}^{\infty}(\beta \gamma)^{t} c_{t}^{e}
$$

where $c_{t}^{e}$ denotes the entrepreneur's consumption at date $t$, and $\gamma \in(0,1)$. This new parameter, $\gamma$, will be chosen so that it offsets the steady-state internal rate of return to entrepreneurs' investment.

At the end of the period, the entrepreneur finances consumption out of the returns from the investment project implying that the law of motion for the entrepreneur's capital stock is

$$
z_{t+1}=n_{t}\left\{\frac{f\left(\bar{\omega} ; \sigma_{\omega, t}\right)}{1-q_{t} g\left(\bar{\omega} ; \sigma_{\omega, t}\right)}\right\}-\frac{c_{t}^{e}}{q_{t}}
$$

Note that the expected return to internal funds is $q_{t} f\left(\bar{\omega} ; \sigma_{\omega, t}\right) i_{t} / n_{t}$; i.e., the net worth of size $n_{t}$ is leveraged into a project of size $i_{t}$, entrepreneurs keep the share of the capital produced and capital is priced at $q_{t}$ consumption goods. Since these are intra-period loans, the opportunity cost is $1 .{ }^{15}$

Consequently, the representative entrepreneur maximizes his expected utility function in Equation (35) over consumption and capital subject to the law of motion for capital, Equation (36), and the definition of net worth given in Equation (2). The resulting Euler equation is as follows:

$$
q_{t}=\beta \gamma E_{t}\left\{\left(q_{t+1}(1-\delta)+r_{t+1}\right)\left(\frac{q_{t+1} f\left(\bar{\omega} ; \sigma_{\omega, t}\right)}{1-q_{t+1} g\left(\bar{\omega} ; \sigma_{\omega, t}\right)}\right)\right\}
$$

\section{Financial Intermediaries}

The Capital Mutual Funds (CMFs) act as risk-neutral financial intermediaries who earn no profit and produce neither consumption nor capital goods. There is a clear role for the CMF in this economy since, through pooling, all aggregate uncertainty of capital production can be eliminated. The CMF receives capital from three sources: entrepreneurs sell undepreciated capital in advance of the loan; after the loan, the CMF receives the newly created capital through loan repayment and through monitoring of insolvent firms; and, finally, those entrepreneurs that are still solvent sell some of their capital to the CMF to finance current period consumption. This capital is then sold at the price of $q_{t}$ units of consumption to households for their investment plans.

\footnotetext{
${ }^{15}$ As noted above, we require in steady state $1=\gamma q_{t} f\left(\bar{\omega}_{t}\right) /\left(1-q_{t} g\left(\bar{\omega}_{t}\right)\right)$. 
Steady-state conditions in the Carlstrom and Fuerst agency cost model We first present the equilibrium conditions and express these in scaled (by the fraction of entrepreneurs in the economy) terms. Then the equations are analysed for steady-state implications. As in the text, upper case variables denote aggregate wide while lower case represent household variables. Preferences and technology are

$$
\begin{aligned}
U(\tilde{c}, 1-l) & =\ln \tilde{c}+\nu(1-l) \\
Y & =\theta K^{\alpha}[(1-\eta) l]^{1-\alpha-\phi} \eta^{\phi}
\end{aligned}
$$

where $\eta$ denotes the fraction of entrepreneurs in the economy and $\theta$ is the technology shock. Note that aggregate household labour is $L=$ $(1-\eta) l$ while entrepreneurs inelastically supply one unit of labour. We assume that the share of the entrepreneur's labour is approximately zero so that the production function is simply

$$
Y=\theta K^{\alpha}[(1-\eta) l]^{1-\alpha}
$$

This assumption implies that entrepreneurs receive no wage income (see Equation (9) in Carlstrom and Fuerst).

There are nine equilibrium conditions.

\section{The resource constraint}

$$
(1-\eta) \tilde{c}_{t}+\eta c_{t}^{e}+\eta i_{t}=Y_{t}=\theta_{t} K_{t}^{\alpha}\left[(1-\eta) l_{t}\right]^{1-\alpha}
$$

Let $c=(1-\eta) \tilde{c} / \eta, h=(1-\eta) l / \eta$ and $k_{t}=K_{t} / \eta$. Then Equation (37) can be written as

$$
c_{t}+c_{t}^{e}+i_{t}=\theta_{t} k_{t}^{\alpha} h_{t}^{1-\alpha}
$$

\section{Household's intratemporal efficiency condition}

$$
\tilde{c}_{t}=\frac{1-\alpha}{\nu} K_{t}^{\alpha}\left[(1-\eta) l_{t}\right]^{-\alpha}
$$

Defining $\nu_{0}=[\eta /(1-\eta)] \nu$, this can be expressed as

$$
\nu_{0} c_{t}=(1-\alpha) k_{t}^{\alpha} h_{t}^{-\alpha}
$$

\section{Law of motion of aggregate capital stock}

$$
K_{t+1}=(1-\delta) K_{t}+\eta i_{t}\left[1-\Phi\left(\bar{\omega} ; \sigma_{\omega, t}\right) \mu\right]
$$

Dividing by $\eta$ yields the scaled version

$$
k_{t+1}=(1-\delta) k_{t}+i_{t}\left[1-\Phi\left(\bar{\omega} ; \sigma_{\omega, t}\right) \mu\right]
$$




\section{Household's intertemporal efficiency condition}

$$
q_{t} \frac{1}{\tilde{c}_{t}}=\beta E_{t}\left\{\frac{1}{\tilde{c}_{t+1}}\left[q_{t+1}(1-\delta)+\theta_{t+1} \alpha K_{t+1}^{\alpha-1}\left[(1-\eta) l_{t+1}\right]^{1-\alpha}\right]\right\}
$$

Dividing both sides by $(1-\eta) / \eta$ and scaling the inputs by $\eta$ yields

$$
q_{t} \frac{1}{c_{t}}=\beta E_{t}\left\{\frac{1}{c_{t+1}}\left[q_{t+1}(1-\delta)+\theta_{t+1} \alpha k_{t+1}^{\alpha-1} h_{t+1}^{1-\alpha}\right]\right\}
$$

The conditions from the financial contract are already in scaled form.

\section{Contract efficiency condition}

$$
q_{t}=\frac{1}{1-\Phi\left(\bar{\omega} ; \sigma_{\omega, t}\right) \mu+\phi\left(\bar{\omega} ; \sigma_{\omega, t}\right) \mu f\left(\bar{\omega} ; \sigma_{\omega, t}\right) / f^{\prime}\left(\bar{\omega}_{t}\right)}
$$

Contract incentive compatibility constraint

$$
\frac{i_{t}}{n_{t}}=\frac{1}{1-q_{t} g\left(\bar{\omega} ; \sigma_{\omega, t}\right)}
$$

where $n_{t}$ is the entrepreneur's net worth.

\section{Determination of net worth}

$$
\eta n_{t}=Z_{t}\left[q_{t}(1-\delta)+\theta_{t} K_{t}^{\alpha-1}\left[(1-\eta) l_{t}\right]^{1-\alpha}\right]
$$

or, in scaled terms,

$$
n_{t}=z_{t}\left[q_{t}(1-\delta)+\theta_{t} k_{t}^{\alpha-1} h_{t}^{1-\alpha}\right]
$$

Note that $z_{t}$ denotes the (scaled) entrepreneur's capital.

Law of motion of the entrepreneur's capital

$$
Z_{t+1}=\eta n_{t}\left\{\frac{f\left(\bar{\omega} ; \sigma_{\omega, t}\right)}{1-q_{t} g\left(\bar{\omega} ; \sigma_{\omega, t}\right)}\right\}-\eta \frac{c_{t}^{e}}{q_{t}}
$$

Or, dividing by $\eta$,

$$
z_{t+1}=n_{t}\left\{\frac{f\left(\bar{\omega} ; \sigma_{\omega, t}\right)}{1-q_{t} g\left(\bar{\omega} ; \sigma_{\omega, t}\right)}\right\}-\frac{c_{t}^{e}}{q_{t}}
$$




\section{Entrepreneur's intertemporal efficiency condition}

$$
\begin{aligned}
q_{t}= & \gamma \beta E_{t}\left\{\left[q_{t+1}(1-\delta)\right.\right. \\
& \left.\left.+\theta_{t+1} \alpha K_{t+1}^{\alpha-1}\left[(1-\eta) l_{t+1}\right]^{1-\alpha}\right]\left(\frac{q_{t+1} f\left(\bar{\omega} ; \sigma_{\omega, t}\right)}{1-q_{t+1} g\left(\bar{\omega} ; \sigma_{\omega, t}\right)}\right)\right\}
\end{aligned}
$$

Or, in scaled terms,

$$
q_{t}=\gamma \beta E_{t}\left\{\left[q_{t+1}(1-\delta)+\theta_{t+1} \alpha k_{t+1}^{\alpha-1} h_{t+1}^{1-\alpha}\right]\left(\frac{q_{t+1} f\left(\bar{\omega} ; \sigma_{\omega, t}\right)}{1-q_{t+1} g\left(\bar{\omega} ; \sigma_{\omega, t}\right)}\right)\right\}
$$

\section{Definition of steady state}

Steady state is defined by time-invariant quantities:

$$
c_{t}=\hat{c}, c_{t}^{e}=\hat{c}^{e}, k_{t}=\hat{k}, \bar{\omega}_{t}=\hat{\omega}, h_{t}=\hat{h}, q_{t}=\hat{q}, z_{t}=\hat{z}, n_{t}=\hat{n}, i_{t}=\hat{\imath}
$$

So there are nine unknowns. While we have nine equilibrium conditions, the two intertemporal efficiency conditions become identical in steady state since Carlstrom and Fuerst impose the condition that the internal rate of return to the entrepreneur is offset by their additional discount factor

$$
\gamma\left(\frac{\hat{q} f(\hat{\omega})}{1-\hat{q} g(\hat{\omega})}\right)=1
$$

This results in an indeterminacy - but there is a block recursiveness of the model due to the calibration exercise. In particular, we demonstrate that the risk premium and bankruptcy rate determine $(\hat{\omega}, \sigma)$ - these in turn determine the steady-state price of capital. From Equation (41) we have

$$
\hat{q}=\frac{\alpha \beta}{1-\beta(1-\delta)} \hat{k}^{\alpha-1} \hat{h}^{1-\alpha}=\frac{\alpha \beta}{1-\beta(1-\delta)} \frac{\hat{y}}{\hat{k}}
$$

From Equation (39) we have

$$
\hat{h}=\frac{1-\alpha}{\nu_{0}} \frac{\hat{k}^{\alpha} \hat{h}^{1-\alpha}}{\hat{c}}=\frac{1-\alpha}{\nu_{0}} \frac{\hat{y}}{\hat{c}}
$$

From Equation (40) we have

$$
\hat{k}=\frac{1-\Phi(\hat{\omega}) \mu}{\delta} \hat{\imath}
$$

Note that these three equations are normally (i.e., in a typical RBC framework) used to find steady state $(\hat{k}, \hat{h}, \hat{c})-$ because $\hat{q}=1$. Here (C) 2008 The Authors. Journal compilation (C) 2008 Blackwell Publishing Ltd and the Board of Trustees of the Bulletin of Economic Research. 
since the price of capital is endogenous, we have four unknowns. From Equation (44)) and Equation (41) we have

$$
\hat{n}=\hat{z}\left(\hat{q}(1-\delta)+\alpha \frac{\hat{y}}{\hat{k}}\right)=\hat{z} \frac{\hat{q}}{\beta}
$$

From Equation (45) and the restriction on the entrepreneur's additional discount factor (Equation (47)), we have

$$
\hat{z}=\hat{n} \frac{1}{\hat{q} \gamma}-\frac{\hat{c}^{e}}{\hat{q}}
$$

Combining Equations (51) and (52) yields

$$
\frac{\hat{c}^{e}}{\hat{n}}=\frac{1}{\gamma}-\beta
$$

We have the two conditions from the financial contract

$$
\hat{q}=\frac{1}{1-\Phi(\hat{\omega}) \mu+\phi(\hat{\omega}) \mu f(\hat{\omega}) / f^{\prime}(\hat{\omega})}
$$

and

$$
\hat{\imath}=\frac{1}{1-\hat{q}(1-\Phi(\hat{\omega}) \mu-f(\hat{\omega}))} \hat{n}
$$

Finally, we have the resource constraint

$$
\hat{c}+\hat{c}^{e}+\hat{\imath}=\hat{k}^{\alpha} \hat{h}^{1-\alpha}
$$

The eight equations (48), (49), (50), (51), (52), (54), (55) and (56) are insufficient to find the nine unknowns. However, the risk premium, denoted as $\zeta$, is defined by the following:

$$
\hat{q} \hat{\omega} \frac{\hat{\imath}}{\hat{\imath}-\hat{n}}=\zeta
$$

But we also know (from Equation (55) that

$$
\frac{\hat{n}}{\hat{\imath}}=1-\hat{q} g(\hat{\omega})
$$

Rearranging Equation (57) yields

$$
\frac{\hat{q} \hat{\omega}}{\zeta}=1-\frac{\hat{n}}{\hat{\imath}}
$$

Substituting from the previous expression yields

$$
\hat{\omega}=\zeta g(\hat{\omega})
$$

Let $b r$ be the bankruptcy rate - this observable also provides another condition on the distribution. That is, we require

$$
\Phi(\hat{\omega})=b r
$$

(C) 2008 The Authors. Journal compilation (C) 2008 Blackwell Publishing Ltd and the Board of Trustees of the Bulletin of Economic Research. 
The two equations Equation (58) and Equation (59) can be solved for the two unknowns $(\hat{\omega}, \sigma)$. By varying the bankruptcy rate and the risk premium, we can determine different levels of uncertainty $(\sigma)$ and the cutoff point $(\hat{\omega})$.

Note that the price of capital in steady state is a function of $(\hat{\omega}, \sigma)$ as determined by Equation (54). The other preference parameter $\gamma$ is then determined by Equation (47). Once this is determined the remaining unknowns $\left(\hat{c}, \hat{c}^{e}, \hat{h}, \hat{\imath}, \hat{k}, \hat{z}, \hat{n}\right)$ are determined by Equations (48), (49), (50), (51), (52), (55) and (56).

Finally, we note that the parameter $\eta$ does not play a role in the characteristics of equilibrium and, in particular, the behaviour of aggregate consumption. This can be seen by first defining aggregate consumption:

$$
(1-\eta) \tilde{c}_{t}+\eta c_{t}^{e}=C_{t}^{A}
$$

Dividing by $\eta$ and using the earlier definitions

$$
c_{t}+c_{t}^{e}=c_{t}^{A}
$$

Since the policy rules for household and entrepreneurial consumption are defined as the percentage deviations from steady state, aggregate consumption will be similarly defined (and note that since $c_{t}^{A}=(1 / \eta) C_{t}^{A}$, percentage deviations of aggregate consumption and scaled aggregate consumption are identical). Using an asterisk to denote percentage deviations from steady state, we have

$$
\frac{\hat{c}}{\hat{c}+\hat{c}^{e}} c_{t}^{*}+\frac{\hat{c}^{e}}{\hat{c}+\hat{c}^{e}} c_{t}^{e *}=c_{t}^{A *}
$$

It is this equation that is used to analyse the cyclical properties of aggregate consumption. 